\title{
The Serum NT-proBNP in Patients with Cirrhosis: Relationship to Cardiac Dysfunction and Liver Function
}

\author{
Hua Mao, Deng-feng Jiang and Li-yun Huang
}

Objective To detect the values of NT-proBNP and evaluate its relationship with liver function, cardiac structure, and cardiac function which was evaluated by echocardiography in patients with liver cirrhosis.

Methods A total of 50 liver cirrhotic patients and 11 healthy controls were studied by two dimensional Doppler echocardiography. Liver cirrhotic patients were divided into group A, B and C according to the Child-Pugh score. Cardiac dimensions and left and right ventricular functions were also evaluated. At the same time, the serum NTproBNP of liver cirrhotic patients and healthy controls were detected, respectively.

Results By Comparison between two groups, we found that the values of LVd, LAs, LVPW, AAO, A Wave, RVOTs, PV and NT-proBNP in liver cirrhosis group were higher than those in control group, whereas the value of E/A decreased. As for the value of LAs and serum NT-proBNP, A and B group were all lower than C group. With LAs $>35 \mathrm{~mm}$, the number of cases in liver cirrhosis group was higher than that in control group. So did that With $\mathrm{E} / \mathrm{A}<1$.

Conclusions The cardiac dysfunction confirmed the existence of cirrhotic cardiomyopathy. More clinical implications were found in liver cirrhotic patients with increased values of serum NT-proBNP.

Key words: Liver cirrhosis; Cirrhotic cardiomyopathy; NT-proBNP; Liver function; Cardiac function

$\mathrm{T}$ The cardiovascular system in patients with liver cirrhosis or portal hypertension is abnormal. The circulation becomes hyperdynamic, characterized by increased cardiac output and decreased peripheral vascular resistance and arterial pressure. ${ }^{1-4}$ Moreover, despite the increased cardiac output at rest, with stressful stimuli such as hemorrhage, surgery or vasoactive drug administration, the ventricular response is blunted, a condition known as cirrhotic cardiomyopathy. ${ }^{5-9}$ These cardiovascular abnormalities have been suggested to induce or aggravate several complications of liver cirrhosis such as sodium and water retention, variceal bleeding, hepatopulmonary syndrome, and increased cardiovascular fragility under stress. ${ }^{10-12}$ In a study of 70 patients with refractory ascites, half treated with transjugular intrahepatic portosystemic stent shunt (TIPSS) and the other half with repeated large volume paracentesis, $12 \%$ patients in the former group developed cardiac failure, compared to none in the latter group. ${ }^{13,14}$ Liver transplantation exerts enormous stresses on the heart; heart-related complications that can occur in the post-operative period include reperfusion syndrome, arrhythmias, sudden cardiac death, myocardial

Department of Gastroenterology, Zhujiang Hospital of Southern Medical University, Guangzhou 510282, China

Correspondence: Li-yun Huang, E-mail:hlydoctor@sina.com infarction and heart failure. ${ }^{15}$ But because of the marked peripheral vasodilatation characteristic of liver cirrhosis, the ventricular afterload is reduced. In other words, the liver cirrhotic patient is almost autoprotected from developing severe or overt heart failure, at least in the absence of a major cardiovascular challenge. ${ }^{16,17}$ So cirrhotic cardiomyopathy does not cause the attention of clinical physicians.

Looking for an effective index to monitor the cardiac dysfunction in patients with liver cirrhosis has great clinical significance. Brain natriuretic peptide (BNP) is one of the important indicators to the evaluation of cardiac function. Some researches have found that plasma BNP values in patients with liver cirrhosis have close relation with liver function and the cardiac dysfunction, may be one of the potential diagnosis symbols of cirrhotic cardiomyopathy. ${ }^{18,19} \mathrm{~N}$-terminal pro-brain natriuretic peptide (NT-proBNP) has been recently suggested to be an even better indicator of early cardiac dysfunction than BNP because of its stability and longer biological half-life. ${ }^{20-22}$ The aim of our study was to evaluate the values of NT-proBNP and its relationship with cardiac structure and cardiac function which was evaluated by echocardiography in patients with liver cirrhosis. Furthermore, we analyzed the relationship between the values of NT-proBNP and liver function. Therefore the aim of our study was 
to clarify the status of the NT-proBNP as makers of cardiac dysfunction in liver cirrhosis.

\section{PATIENTS AND METHODS}

\section{Patients}

Toatal of 50 patients with cirrhosis (12 female, 38 male, mean age $53.16 \pm 12.42$ years old) were enrolled. Liver cirrhosis was diagnosed by liver biopsy or by clinical, laboratory, ultrasonographic, and endoscopic findings. The origin of liver cirrhosis was hepatitis $B$ in 33 patients, hepatitis $C$ in 3 patients, mixed type (hepatitis B + hepatitis C) in 1 patient, ethanolrelated in 7 patients, primary biliary cirrhosis in 2 patients, cryptogenic in 4 patients. Cirrhotic patients were divided into group $\mathrm{A}, \mathrm{B}$ and $\mathrm{C}$ according to the Child-Pugh score (including 15 patients with Child class A, 20 patients with Child class B and 15 patients with Child class C). Besides, 11 age-matched healthy volunteers ( 4 female, 7 male, mean age $52.55 \pm 7.65$ years old) were taken as controls. The nature of the study was explained to the patients and informed consent was obtained from all cases.

\section{Exclusion criteria}

Patients were excluded from the study if they had a history or clinical evidence of a major cardiovascular disease, a major lung disease, or a systemic disease. Other exclusion criteria were the following: (1) terminal liver failure; (2) major arrhythmias; (3) recent hemorrage $(<1$ month); (4) recent ethanol consumption ( $<3$ months); (5) history or sphygmomanometric evidence of arterial hypertension; (6) treatment with any drug which could affect the parameters under study such as sympathomimetic amines, beta blockers, nitrates, and any antihypertensive agent. ${ }^{23}$

\section{Blood test}

All the patients and controls were conducted for routine blood, kidney and liver function, coagulation function before treatment. The major parameters including WBC $(\mathrm{g} / \mathrm{L}), \operatorname{RBC}(\mathrm{T} / \mathrm{L})$, PLT $(\mathrm{g} / \mathrm{L})$, ALB $(\mathrm{g} / \mathrm{L})$, TBil $(\mu \mathrm{mol} / \mathrm{L})$, CR $(\mu \mathrm{mol} / \mathrm{L})$, PT (s), APTT (s).

\section{Echocardiography}

Echocardiography was performed by a 2.5 or 3.5 $\mathrm{MHz}$ phased array transducer probe through the left parasternal view and the apical four-chamber subcostal view. The echocardiographic measures included left ventricular diameters (LVd), right ventricular diameters (RVd) and left atrium diameters (LAs), the thickness of the left posterior ventricular wall (LVPW) and the interventricular septum (IVS), left ventricular ejection fraction (LVEF), left ventricular outflow tract diam (LVOTs), right ventricular outflow tract diam (RVOTs), aortic diameter (AAO), the peak filling velocity during early ventricle diastole ( $E$ wave) and the filling velocity during atrial systole (A wave), the $\mathrm{E}$ waveto-A wave ratio (E/A), and the Doppler analysis of mitral flow velocity (MV), pulmonary flow velocity $(\mathrm{PV})$ and aortic flow velocity (AV).

\section{Detection of NT-proBNP}

Blood samples was obtained from a forearm vein after at least 10 minutes' resting supine, and was collected in standard sampling tubes for NT-proBNP analysis. Then specimen was centrifuged for serum. The serum was storaged in $180^{\circ} \mathrm{C}$ refrigerator for detection of NTproBNP. And NT-proBNP values were detected by an ELISA kit (Blue based Biotechnology Co, Ltd), with the detection sensitivity as $1 \mathrm{pg} / \mathrm{ml}$.

\section{Statistical analysis}

All statistical analysis was performed with SPSS software version 13.0, and data were expressed as mean $\pm \mathrm{SD}$. The ratios were compared by Chi-square test. Comparison between liver cirrhosis group and control group was performed by two-sample $t$-test. While comparison among groups $\mathrm{A}, \mathrm{B}, \mathrm{C}$ was performed by a standard one-way analysis of variance. If variance was homogeneous, then LSD multiple comparison was carried out. While if variance was not homogeneous, then Dunnett's T3 multiple comparison was applied. The spearman correlation analysis was taken to analyze the relationship among different factors. A two-tailed $P$ value of less than 0.05 was considered statistically significant.

\section{RESULTS}

\section{Characteristics of patient included}

As for age and gender, there was no difference between control group and cirrhotic group, also among A, B, C groups $(P>0.05$, Table 1$)$.

The comparison of routine blood, kidney and liver function, coagulation function between group A, B and $\mathrm{C}$

The comparison of routine blood, kidney and liver function, coagulation function in group A, B and C were shown in Table 2. In general, we found that the values of ALB and PT(s) were significantly different among the three groups $(P<0.05)$. With the ChildPugh grade rising, the value of ALB decreased, while the PT(s) increased. But there was no significant difference among group $\mathrm{A}, \mathrm{B}$ and $\mathrm{C}$ on the value of other indexes. Otherwise, multiple comparison was applied to compare routine blood, kidney and liver function, coagulation function between the three groups. The results showed that compared with group 
Table 1. Characteristics of patient included

\begin{tabular}{lcc}
\hline Groups & Age $(\bar{x} \pm s$, years old $)$ & Gender (male/female) \\
\hline Control group $(\mathrm{n}=11)$ & $52.55 \pm 7.65$ & $7 / 11$ \\
Cirrhotic group $(\mathrm{n}=50)$ & $53.16 \pm 12.42$ & $38 / 50$ \\
Group A $(\mathrm{n}=15)$ & $51.00 \pm 14.46$ & $13 / 15$ \\
Group B $(\mathrm{n}=20)$ & $54.45 \pm 13.16$ & $16 / 20$ \\
Group C $(\mathrm{n}=15)$ & $53.60 \pm 9.38$ & $9 / 15$ \\
\hline
\end{tabular}

Table 2. Comparison of routine blood, kidney and liver function, coagulation function between groups A, B and C

\begin{tabular}{|c|c|c|c|c|}
\hline Indexes & Group A & Group B & Group C & $F / P$ \\
\hline $\operatorname{WBC}(\bar{x} \pm s, \mathrm{~g} / \mathrm{L})$ & $5.39 \pm 5.39$ & $4.54 \pm 2.10$ & $5.42 \pm 3.11$ & $0.338 / 0.715$ \\
\hline $\operatorname{RBC}\left(\bar{x}^{ \pm s}, \mathrm{~T} / \mathrm{L}\right)$ & $3.69 \pm 0.77$ & $3.48 \pm 0.67$ & $3.01 \pm 0.73^{\mathrm{a}}$ & $3.540 / 0.037$ \\
\hline $\operatorname{PLT}(\bar{x} \pm s, \mathrm{~g} / \mathrm{L})$ & $89.44 \pm 45.75$ & $114.46 \pm 78.48$ & $89.55 \pm 50.84$ & $0.963 / 0.389$ \\
\hline $\operatorname{ALB}\left(\bar{x}^{ \pm s}, \mathrm{~g} / \mathrm{L}\right)$ & $37.49 \pm 3.61$ & $30.97 \pm 4.04^{\mathrm{a}}$ & $27.43 \pm 3.29^{\mathrm{ab}}$ & $28.676 / 0.000$ \\
\hline $\operatorname{TBil}\left(\bar{x}^{ \pm s}, \mu \mathrm{mol} / \mathrm{L}\right)$ & $17.41 \pm 8.08$ & $61.41 \pm 102.12$ & $90.74 \pm 136.58^{\mathrm{a}}$ & $2.092 / 0.135$ \\
\hline $\mathrm{CR}\left(\bar{x}^{ \pm s, \mu \mathrm{mol} / \mathrm{L})}\right.$ & $82.67 \pm 19.50$ & $85.35 \pm 18.30$ & $85.13 \pm 21.20$ & $0.093 / 0.912$ \\
\hline $\mathrm{PT}\left(\bar{x}^{ \pm s, \mathrm{~S}}\right)$ & $15.33 \pm 1.07$ & $16.36 \pm 1.93$ & $18.32 \pm 2.67^{\mathrm{ab}}$ & $8.736 / 0.001$ \\
\hline $\operatorname{APTT}\left(\bar{x}^{ \pm} s, \mathrm{~S}\right)$ & $42.35 \pm 5.43$ & $41.85 \pm 5.35$ & $43.43 \pm 4.85$ & $0.399 / 0.673$ \\
\hline
\end{tabular}

Notes: ${ }^{\mathrm{a}}$ compared with Group A, $P<0.05 ;{ }^{\mathrm{b}}$ compared with Group B, $P<0.05$

Table 3. Cardiac echocardiography and NT-proBNP in cirrhotic patients and controls

\begin{tabular}{|c|c|c|c|c|}
\hline Groups & Control group & Cirrhotic group & $t$ values & $P$ values \\
\hline $\operatorname{LVd}\left(\bar{x}^{ \pm s, \mathrm{~mm}}\right)$ & $41.36 \pm 2.38$ & $43.54 \pm 4.45$ & 2.280 & 0.030 \\
\hline $\operatorname{LAs}\left(\bar{x}^{ \pm s, \mathrm{~mm}}\right)$ & $27.25 \pm 2.66$ & $31.91 \pm 4.09$ & 3.605 & 0.001 \\
\hline $\operatorname{LVOTs}\left(\bar{x}^{ \pm s, \mathrm{~mm}}\right)$ & $18.74 \pm 1.45$ & $19.50 \pm 2.61$ & 0.939 & 0.352 \\
\hline $\operatorname{RVd}\left(\bar{x}^{ \pm s, \mathrm{~mm}}\right)$ & $19.33 \pm 2.15$ & $18.57 \pm 2.09$ & -1.089 & 0.281 \\
\hline $\operatorname{RVOTs}\left(\bar{x}^{ \pm s}, \mathrm{~mm}\right)$ & $21.53 \pm 2.38$ & $23.90 \pm 2.62$ & 2.756 & 0.008 \\
\hline $\operatorname{IVS}\left(\bar{x}^{ \pm s, \mathrm{~mm}}\right)$ & $9.39 \pm 1.11$ & $10.10 \pm 1.09$ & 1.963 & 0.054 \\
\hline $\operatorname{LVPW}\left(\bar{x}^{ \pm s, \mathrm{~mm}}\right)$ & $9.36 \pm 0.76$ & $9.86 \pm 1.04$ & 2.174 & 0.032 \\
\hline $\mathrm{AV}\left(\bar{x}^{ \pm s, \mathrm{~m} / \mathrm{s})}\right.$ & $1.20 \pm 0.29$ & $1.28 \pm 0.30$ & 0.745 & 0.459 \\
\hline $\operatorname{MV}\left(\bar{x}^{ \pm s, \mathrm{~m} / \mathrm{s})}\right.$ & $0.89 \pm 0.29$ & $0.94 \pm 0.16$ & 0.778 & 0.440 \\
\hline $\mathrm{PV}\left(\bar{x}^{ \pm s, \mathrm{~m} / \mathrm{s}}\right)$ & $0.91 \pm 0.16$ & $1.06 \pm 0.22$ & 2.144 & 0.036 \\
\hline $\mathrm{AAO}\left(\bar{x}^{ \pm s, \mathrm{~mm}}\right)$ & $25.51 \pm 1.18$ & $28.10 \pm 3.30$ & 4.411 & 0.000 \\
\hline $\mathrm{EF}\left(\bar{x}^{ \pm s, \%)}\right.$ & $60.27 \pm 1.27$ & $59.79 \pm 3.02$ & -0.514 & 0.609 \\
\hline E wave $\left(\bar{x}^{ \pm s}\right)$ & $0.87 \pm 0.30$ & $0.79 \pm 0.21$ & -0.955 & 0.344 \\
\hline A wave $\left(\bar{x}^{ \pm s}\right)$ & $0.68 \pm 0.14$ & $0.82 \pm 0.21$ & 2.123 & 0.038 \\
\hline $\mathrm{E} / \mathrm{A}\left(\bar{x}^{ \pm s}\right)$ & $1.29 \pm 0.45$ & $1.01 \pm 0.35$ & -2.248 & 0.028 \\
\hline NT-proBNP $\left(\bar{x}^{ \pm s, p g / m l}\right)$ & $87.29 \pm 32.14$ & $161.87 \pm 69.07$ & 5.420 & 0.000 \\
\hline
\end{tabular}

A, the value of RBC decreased, while the value of TBil increased in group C, but the difference was not significant compared with group B.

\section{Cardiac echocardiography and NT-proBNP in} cirrhotic patients and controls

The results showed that the values of LVd, LAs, LVPW, AAO, A Wave RVOTs, PV and NT-proBNP in liver cirrhosis group increased compared with those in control group $(P<0.05$, respectively). The values of $\mathrm{E} / \mathrm{A}$ in liver cirrhosis group decreased compared with the control group $(P<0.05)$. There's no significant difference for the values of LVOTs, RVd, IVS, AV, $\mathrm{MV}, \mathrm{EF}$, and $\mathrm{E}$ wave between liver cirrhosis group and control group. 
Table 4. The ratios of $L A s>35 \mathrm{~mm}$ and $E / A<1$ between control and cirrhotic groups

\begin{tabular}{lll}
\hline Groups $(\mathrm{n})$ & LAs $>35 \mathrm{~mm}$ & $\mathrm{E} / \mathrm{A}<1$ \\
\hline Control group $(\mathrm{n}, \%)$ & $0 / 11(0)$ & $2 / 11(18.2)$ \\
Cirrhotic group (n, \%) & $17 / 50(34)$ & $28 / 50(56)$ \\
$P$ value & 0.025 & 0.043 \\
\hline
\end{tabular}

Table 5. Cardiac function and NT-proBNP among groups A, B and C

\begin{tabular}{|c|c|c|c|c|}
\hline Groups & Group A & Group B & Group C & $\mathrm{F} / \mathrm{P}$ \\
\hline $\operatorname{LVd}\left(\bar{x}^{ \pm s, \mathrm{~mm}}\right)$ & $45.05 \pm 4.94$ & $42.06 \pm 3.71$ & $44.01 \pm 4.52$ & $2.144 / 0.129$ \\
\hline LAs $(\bar{x} \pm s, \mathrm{~mm})$ & $31.74 \pm 4.04$ & $29.75 \pm 3.03$ & $34.97 \pm 3.58^{\mathrm{ab}}$ & $9.445 / 0.000$ \\
\hline $\operatorname{RVd}\left(\bar{x}^{ \pm s, \mathrm{~mm}}\right)$ & $19.17 \pm 1.86$ & $18.34 \pm 1.61$ & $18.27 \pm 2.78$ & $0.886 / 0.419$ \\
\hline $\operatorname{IVS}\left(\bar{x}^{ \pm s, \mathrm{~mm}}\right)$ & $9.95 \pm 1.12$ & $10.36 \pm 0.99$ & $9.92 \pm 1.19$ & $0.923 / 0.404$ \\
\hline $\operatorname{LVPW}\left(\bar{x}^{ \pm s, \mathrm{~mm}}\right)$ & $9.55 \pm 1.49$ & $9.60 \pm 1.07$ & $9.94 \pm 1.03$ & $0.479 / 0.622$ \\
\hline $\mathrm{AAO}\left(\bar{x}^{ \pm s, \mathrm{~mm}}\right)$ & $27.45 \pm 4.43$ & $28.65 \pm 2.75$ & $28.01 \pm 2.72$ & $0.560 / 0.575$ \\
\hline $\mathrm{EF}(\bar{x} \pm s, \%)$ & $60.33 \pm 2.23$ & $59.60 \pm 2.74$ & $59.46 \pm 4.19$ & $0.348 / 0.708$ \\
\hline E wave $\left(\bar{x}^{ \pm s}\right)$ & $0.85 \pm 0.16$ & $0.73 \pm 0.22$ & $0.82 \pm 0.22$ & $1.603 / 0.212$ \\
\hline A wave $\left(\bar{x}^{ \pm s}\right)$ & $0.88 \pm 0.21$ & $0.77 \pm 0.21$ & $0.84 \pm 0.20$ & $1.276 / 0.289$ \\
\hline $\mathrm{E} / \mathrm{A}\left(\bar{x}^{ \pm s}\right)$ & $1.03 \pm 0.32$ & $1.02 \pm 0.40$ & $0.99 \pm 0.33$ & $0.042 / 0.959$ \\
\hline $\operatorname{NT}$-proBNP $\left(\bar{x}^{ \pm s, p g / m l}\right)$ & $124.1 \pm 50.13$ & $144.3 \pm 42.28$ & $222.87 \pm 76.25^{\mathrm{ab}}$ & $12.987 / 0.000$ \\
\hline
\end{tabular}

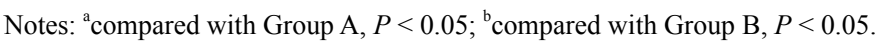

Table 6. The correlationship between NT-proBNP and parameters of echocardiographic and liver function in cirrhotic patients

\begin{tabular}{lcc}
\hline NT-proBNP & Correlation coefficients & $P$ values \\
\hline LVd & 0.227 & 0.113 \\
LAs & 0.540 & 0.000 \\
IVS & 0.101 & 0.485 \\
LVPW & 0.309 & 0.029 \\
EF & -0.059 & 0.693 \\
E/A & 0.025 & 0.865 \\
CTP & 0.454 & 0.001 \\
ALB & -0.376 & 0.007 \\
TBIL & 0.283 & 0.047 \\
CR & 0.152 & 0.293 \\
\hline
\end{tabular}

The ratios of $\mathrm{LAs}>35 \mathrm{~mm}$ and $\mathrm{E} / \mathrm{A}<1$ between control and cirrhotic groups

When LAs $>35 \mathrm{~mm}$, left atrium enlargement is defined. And $\mathrm{E} / \mathrm{A}<1$ is a sensitive parameter indicating diastolic left ventricular dysfunction. According to the level of LAs and E/A, We divided the controls and cirrhotic patients into two groups, (LAs $\leqslant 35 \mathrm{~mm}$ and LAs $>35 \mathrm{~mm}$; $\mathrm{E} / \mathrm{A} \geqslant 1$ and $\mathrm{E} / \mathrm{A}<1)$. In liver cirrhosis group, there were 17 cases with LAs $>35 \mathrm{~mm}(17 / 50$, $34 \%$, while no case with LAs $>35 \mathrm{~mm}(0 / 11,0 \%)$ in the control group. There were 28 patients with $\mathrm{E} / \mathrm{A}<$ $1(28 / 50,56 \%)$ in liver cirrhosis group and 2 controls with $\mathrm{E} / \mathrm{A}<1(2 / 11,18.2 \%)$ in control group (Table 4$)$. And the differences were both significant between the control group and cirrhotic group $(P<0.05)$.

\section{Cardiac function and NT-proBNP among group $A$, $B$ and $C$}

From Table 5, we can conclude that the values of LAs and serum NT-proBNP for group A and B were all lower than those of group $\mathrm{C}(P<0.05)$, but the difference was not significant between group $\mathrm{A}$ and B $(P>0.05)$. Meanwhile, there was no significant difference among group $\mathrm{A}, \mathrm{B}$ and $\mathrm{C}$ for other 
parameters.

\section{The correlationship between NT-proBNP and parameters of echocardiographic and liver function in cirrhotic patients}

Correlation analysis showed that the value of NTproBNP was positively correlated with LAs and LVPW. In addition, NT-proBNP was correlated with ChildPugh score (CTP), the values of albumin and total bilirubin (Table 6).

\section{DISCUSSION}

The occurrence of cardiac function abnormalities in cirrhotic patients has drawn a few attentions, although clinical symptoms of cardiac impairment at rest are usually not apparent. By means of echocardiography, some studies carried out a noninvasive assessment of cardiac dimension and systolic and diastolic function in cirrhotic patients at rest and elicited that some morphological and functional parameters may be taken as early markers of cardiac abnormalities in liver cirrhosis. ${ }^{17,24}$ In our research, we found that the values of LVd, LAs increased in liver cirrhosis group compared with those in healthy group. Atrial enlargement has been regarded as a marker of the severity and duration of diastolic dysfunction. ${ }^{25}$ There was a significant difference for LAs between liver cirrhosis group and control group, which indicated that the patients with liver cirrhosis appeared left heart diastolic and systolic dysfunction. Comparison among group A, B and C showed that the values of Las in group $\mathrm{A}$ and $\mathrm{B}$ were lower than those in group $\mathrm{C}(P$ $<0.05)$, but there was no difference between group A and group B, which Suggested that further decline of left heart function indicate the deterioration of liver function. According to the results of echocardiography, when the value of Las was higher than $35 \mathrm{~mm}$, then left atrium enlargement was defined. In liver cirrhosis group, there were 17 cases with LAs $>35 \mathrm{~mm}$, while no case with LAs $>35 \mathrm{~mm}$ in control group, which showen that the probability of left atrium enlargement in liver cirrhosis patients was higher than those in controls. We also found that the value of LVPW in liver cirrhosis group was higher than that in control group $(P<0.05)$. The thickening of LVPW can lower left ventricular compliance and influence the filling and diastolic function of left ventricular. Necropsy studies revealed that some patients with liver cirrhosis have histological or structural abnormalities of heart. Histological changes include myocardial fibrosis, subendocardial edema, nuclear and cytoplasmic vacuolation of cardiomyocytes. Structural changes also can be found in the left heart, rather than in the right heart (including dilatation of the left atrium, hypertrophy or dilatation of the left ventricle in the cardiac chambers). ${ }^{26-30}$ Generally, the dimensions and wall thickness of the right atrium and right ventricle were normal. Our results was in consistent with that of necropsy studies in cirrhotic patients, which confirmed that the dysfunction of cardiac in patients with liver cirrhosis often occurred in the left heart rather than the right.

It is recommended that the value of $\mathrm{E} / \mathrm{A}$ ratio represent diastolic function of left ventricular. And the opinion of $\mathrm{E} / \mathrm{A}<1$ indicating diastolic left ventricular dysfunction has been accepted. ${ }^{31}$ Comparison of the value of E/A showed significant difference between control group and liver cirrhosis group, but with no difference among group A, B and C. And in this study, there were 28 patients $(28 / 50,56 \%)$ with $\mathrm{E} / \mathrm{A}<1$ in liver cirrhosis group and only 2 cases $(18.2 \%, 2 / 11)$ in control group, with significant difference. This suggested that the probability of $\mathrm{E} / \mathrm{A}<1$ in patients with liver cirrhosis was higher than that in controls, and cardiac diastolic dysfunction more likely occurred in patients with liver cirrhosis. Massimo et al even found that assessment of diastolic function by the ratio of $\mathrm{E} /$ A could be applied to predict the long-term survival situation after TIPSS in patients with liver cirrhosis, and a low E/A ratio was shown to be an independent risk factor for predicting death in patients with TIPSS. ${ }^{32}$

Peripheral vasodilatation is the key to hyperdynamic circulation and portal hypertension in liver cirrhosis. However, the factors directly initiating the vasodilatation remain obscure. A hypothesis that has received much attention over the past three decades is the "humoral factor" theory. In liver cirrhosis, increased intrahepatic resistance induces portosystemic collateral formation, allowing gutlderived humoral substances to directly enter the systemic circulation without detoxification by the liver. The following gut derived or locally produced humoral factors have been implicated as possible mediators of peripheral vasodilatation in liver cirrhosis or portal hypertension. ${ }^{33}$ In our research, we found that the value of AAO in patients with liver cirrhosis was higher than that in control group. The increase of AAO in patients with liver cirrhosis means decrease of peripheral vascular resistance which could lead to conceal of the cardiac dysfunction. While the difference between liver cirrhosis group and control group for LVEF was not significant. But due to the increase in $\mathrm{LVd}$, each cardiac output increased relatively. At the same time, we found RVOTs and PV in liver cirrhosis group increased compared with that in control group, which could lead to blood backflow to pulmonary vascular system faster. Combined with the existing left heart diastolic dysfunction, pulmonary circulatory stasis which may affect lung ventilation perfusion ratio imbalance could be caused. So cardiac 
dysfunction of cirrhotic patients may take part in the occurrence of hepatopulmonary syndrome. In the study by Bernal et al, they found pulmonary capillary wedge pressure elevated in patients with liver cirrhosis by right cardiac catheterization. ${ }^{34}$ This change might be related to the increase of RVOTs and PV.

The natriuretic peptides have recently been highlighted as major markers for the diagnosis, severity, and prognosis of heart failure. B-type natriuretic peptide (BNP) is a neurohormone synthesized in cardiac ventricles. BNP is released as preproBNP and then enzymatically cleaved to NT-proBNP and BNP, depending on ventricular myocyte stretching and volume overload. In cases with heart failure, ventricular BNP production is markedly elevated, and circulating BNP concentrations are consistently elevated in untreated heart failure. Accordingly, blood measurements of BNP and NT-proBNP have been found to be of diagnostic value in congestive heart failure (CHF) related to CHF severity. But NT-proBNP has recently been suggested to be an even better marker of early cardiac dysfunction or heart failure than BNP, because it is more stable and less sensitive to rapid fluctuations caused by short-term secretion stimuli due to its longer biological half-life. ${ }^{35-38}$ Some researches found that the plasma BNP levels in patients with liver cirrhosis have close relationship with live function and the cardiac dysfunction. In our study, serum NTproBNP levels were found to be significantly higher in cirrhotic patients than in controls $(161.87 \pm 69.07 \mathrm{pg} / \mathrm{ml}$ vs $87.29 \pm 32.14 \mathrm{pg} / \mathrm{ml}$ ). In addition, serum NT-proBNP levels were also higher in group $\mathrm{C}$ than in group $\mathrm{A}$ or B. Furthermore, a significant correlationship was observed between NT-proBNP and Child-Pugh score $(r$ $=0.454, P=0.001)$, the values of albumin $(r=10.376$, $P=0.007)$, and the values of total bilirubin $(r=0.283$, $P=0.047)$. These results suggested that serum NTproBNP level was likely to be related to the severity of liver cirrhosis.

The increase of serum NT1proBNP can be the result of impaired systolic function or diastolic relaxation. The fact that elevated levels of NT-proBNP can identify asymptomatic patients with diastolic dysfunction in the absence of systolic abnormalities has made it a useful screening tool for the detection of cardiac dysfunction. In our study, correlationship analysis showed that NT-proBNP had positive correlationship with LAs and LVPW in cirrhotic patients $(r=0.540$, $P=0.000 ; r=0.309, P=0.029$, respectively). A research by Henriksen showed that circulating proBNP concentrations significantly increased in patients with advanced cirrhosis. However, no signs of reduced proBNP were found in patients with cirrhosis, which suggested that elevated level of proBNP was a marker of cirrhotic severity and predicted the presence of cardiac dysfunction. ${ }^{18}$

In conclusion, the cardiac systolic and diastolic function of patients with cirrhosis are deficient, and diastolic dysfunction is given priority to systolic dysfunction. The cardiac dysfunction confirmed the existence of cirrhotic cardiomyopathy. The degree of cardiac insufficiency is related to the damage of liver function. More attention to the possibility of cirrhotic cardiomyopathy in the condition of LAs $>35 \mathrm{~mm}$ and E $/ \mathrm{A}<1$ should be paid. More clinical implications were found in cirrhotic patients with increased values of serum NT-proBNP. It may be suggested that an increased serum NT-proBNP values has predictive value in cases of concomitant cardiac dysfunction and cirrhotic progression.

\section{Conflicts of interest}

No potential conflict of interest relevant to this article was reported.

\section{REFRENCES}

1. Kowalski HJ, Abelmann WH. The cardiac output at rest in Laennec cirrhosis. J Clin Invest 1953;32:1025-1033.

2. Kelbaek H, Eriksen J, Brynjolf I, Raboel A, Lund JO, Munck O, et al. Cardiac performance in patients with asymptomatic alcoholic cirrhosis of liver. Am J Cardiol 1984;54:852-855.

3. Ruiz-del-Arbol L, Monescillo A, Arocena C, Valer P, Ginès P, Moreira V, et al. Circulatory function and hepatorenal syndrome in cirrhosis. Hepatology 2005;42:439-447.

4. Bernal V, Pascual I, Esquivias P, García-Gil A, Fernández C, Mateo JM, et al. Cardiac hemodynamic profiles and pro-Btype natriuretic peptide in cirrhotic patients undergoing liver transplantation. Transplant Proc 2009;41:985-986.

5. Milani A, Zaccaria R, Bombardieri G, Gasbarrini A, Pola P. Cirrhotic cardiomyopathy. Dig Liver Dis 2007; 39:507-515.

6. Grose RD, Nolan J, Dillon JF, Errington M, Hannan WJ, Bouchier IA, et al. Exercise-induced left ventricular dysfunction in alcoholic and nonalcoholic cirrhosis. J Hepatol 1995;22:326-332.

7. Wang F, Girgrah N, Graba J. The cardiac response to exercise in cirrhosis. Gut 2001;49:268-275.

8. Lee SS. Cardiac dysfunction in spontaneous bacterial peritonitis: a manifestation of cirrhotic cardiomyopathy? Hepatology 2003;38:1089-1091.

9. Henriksen JH, Fuglsang S, Bendtsen F, Christensen E, Møller S. Dyssynchronous electrical and mechanical systole in patients with cirrhosis. J Hepatol 2002;36:513-520.

10. Ruiz-del-Arbol L, Urman J, Fernández J, González M, Navasa M, Monescillo A, et al. Systemic, renal, and hepatic hemodynamic derangement in cirrhotic patients with spontaneous bacterial peritonitis. Hepatology 2003;38:1210-1218.

11. Liu H, Gaskari SA, Lee SS. Cardiac and vascular changes in cirrhosis: Pathogenic mechanisms. World J Gastroenterol 2006; 12:837-842.

12. Moller S, Henriksen JH. Cirrhotic cardiomyopathy: a pathophysiological review of circulatory dysfunction in 1iver disease. Heart 2002;87:9-15.

13. Ginès P, Uriz J, Calahorra B, Garcia-Tsao G, Kamath PS, Del Arbol LR, et al. Transjugular intrahepatic portosystemic shunting versus paracentesis plus albumin for refractory ascites in cirrhosis. Gastroenterology 2002;123:1839-1847.

14. Schwartz JM, Beymer C, Althaus SJ, Larson AM, Zaman A, Glickerman DJ, et al. Cardiopulmonary consequences of transjugular intrahepatic portosystemic shunts: role of increased pulmonary artery pressure. J Clin Gastroenterol 2004;38:590-594. 
15. Lee RF, Glenn TK, Lee SS. Cardiac dysfunction in cirrhosis. Best Pract Res Clin Gastroenterol. 2007;21:125-140.

16. Valeriano V, Funaaro S, Lionetti R. Modification of cardiac function in cirrhotic patients with and without ascites. Am J Gastroenterol 2000;36:3200-3205.

17. Zardi EM, Abbate A, Zardi DM, Dobrina A, Margiotta D, Van Tassell BW, et al. Cirrhotic cardiomyopathy. J Am Coll Cardiol 2010;7:539-549.

18. Henriksen JH, Gøtze JP, Fuglsang S, Christensen E, Bendtsen $\mathrm{F}$, Møller S. Increased circulating pro-brain natriuretic peptide (proBNP) and brain natriuretic peptide (BNP) in patients with cirrhosis: relation to cardiovascular dysfunction and severity of disease. Gut 2003;52:1511-1517.

19. Yildiz R, Yildirim B, Karincaoglu M, Harputluoglu M, Hilmioglu F. Brain natriuretic peptide and severity of disease in non-alcoholic cirrhotic patients. J Gastroenterol Hepatol 2005;20:1115-1120.

20. Petr J. Serum biomarkers for heart failure. Cardiovasc Pathol. 2006; $15: 144-149$.

21. Mark R, Richard W. NT-proBNP in heart failure: therapy decisions and monitoring. Eur J Heart Fail 2004;6:351-354.

22. Palazzuoli A, Gallotta M, Quatrini I. Natriuretic peptides (BNP and NT-proBNP): measurement and relevance in heart failure. Vasc Health Risk Manag 2010;6:411-418.

23. Pozzi M, Carugo S, Boari G, Pecci V, de Ceglia S, Maggiolini S, et al. Evidence of functional and structural cardiac abnormalities in cirrhotic patients with and without ascites. Hepatology 1997;11:1131-1137.

24. La Villa G, Gentilini P. Hemodynamic alterations in liver cirrhosis. Mol Aspects Med 2008;29:112-118.

25. Pozzi M, Carugo S, Boari G, Pecci V, de Ceglia S, Maggiolini S, et al. Diastolic dysfunction and left atrial volume: A populationbased study. J Am Coll Cardiol. 2005;45:87-92.

26. Ma Z, Lee SS. Cirrhotic cardiomyopathy: getting to the heart of the matter. Hepatology 1996;24:451-459.
27. Liu H, Lee SS. Cardiopulmonary dysfunction in cirrhosis. J Gastroenterol Hepatol 1999;14:600-608.

28. Liu H, Song D, Lee SS. Cirrhotic cardiomyopathy. Gastroenterol Clin Biol 2002;26:842-847.

29. Baik SK, Fouad TR, Lee SS. Cirrhotic cardiomyopathy. Orphanet J Rare Dis 2007;2:15.

30. Soon KB, Samuel SL. Cirrhotic cardiomyopathy: causes and consequences. J Gastroenterol Hepatol 2004;19:185-190.

31. Ommen SR. Echocardiographic assessment of diastolic function. Curr Opin Cardiol 2001;16:240-245.

32. Cazzaniga M, Salerno F, Pagnozzi G, Dionigi E, Visentin S, Cirello I, et al. Diastolic dysfunction is associated with poor survival in patients with cirrhosis with transjugular intrahepatic portosystemic shunt. Gut 2007;56:869-875.

33. Moller S, Henriksen JH. Cirrhotic cardiomyopathy. J Hepatol 2010;53:179-190.

34. Bernal V, Pascual I, Lanas A, Esquivias P, Piazuelo E, GarciaGil FA, et al. Cardiac function and aminoterminal pro-brain natriuretic peptide values in liver-transplanted cirrhotic patients. Clin Transplant 2012;26:111-116.

35. Matsuo H. Discovery of a natriuretic peptide family and their clinical application. Can J Physiol Pharmacol 2001;79:736-740.

36. Boomsma F. Plasma A- and B-type natriuretic peptides: physiology, methodology and clinical use. Cardiovasc Res 2001;51:442-449.

37. Cea LB. Natriuretic peptide family: new aspects. Curr Med Chem Cardiovasc Hematol Agents 2005;3:87-98.

38. Richards M, Troughton RW. NT-proBNP in heart failure: therapy decisions and monitoring. Eur J Heart Fail 2004;6:351-354. 